\title{
Social Factors Contributing to Students' Substance Abuse in Dire Dawa University
}

\author{
Lina Deribe Shiferaw \\ Haramaya University, College of Education and Behavioral Science, Department of Psychology, Haramaya , \\ Ethiopia
}

\begin{abstract}
The objective of this study was to assess Social Factors Contributing to Students" Substance Abuse in Dire Dawa University. this study employed descriptive survey design. The study employed descriptive survey research design and stratified random sampling and purposive sampling techniques to select students and key informants respectively. The data were collected by questionnaire, interview and document review. Questioner and interview respectively collected the data from students and key informants. To analyze the collected data frequency, percentage, mean, standard deviation, chi-square test, binomial logistic regression and narrative description were applied. The finding of the study revealed that $66.6 \%$ of respondents abused substance. Male students $(62.8 \%)$ were highly abuse substance than female students $(37.2 \%)$. Besides, khat was highly abused substance $(56 \%)$. Khat is frequently abused substance $(\mathrm{M}=4.78, \mathrm{SD}=0.57)$ followed by alcohol $(\mathrm{M}=4.23, \mathrm{SD}=0.68)$ and cigarette $(\mathrm{M}=4.01, \mathrm{SD}=0.81)$. Higher numbers of the respondents abuse substance (CAGE $\geq 2=39 \%)$. In addition, the study revel that substance abuse was a leading factor toward illicit drug abuse. Furthermore, the study indicates that among social factors availability of substance in cloth distance around the campus was highly predictor of substance abuse $(\mathrm{COR}=6.52: 95 \% \mathrm{CI} 2.76,6.92)$ followed by family substance abuse history $(\mathrm{COR}=3.07: 95 \% \mathrm{CI}$ 1.74,5.41) social acceptance $(\mathrm{COR}=3.04: 95 \%$ CI 4.56,5.21) and, peer pressure $(\mathrm{COR}=2.30: 95 \%$ CI $1.79,5.22)$ among students. The study also revealed there is no significant preference on substance abuse among male and female students ( ${ }^{2}(1)=3.514, \mathrm{P}>0.05$, one-tailed). whereas café utilization (café or non-café) $\left({ }^{2}(1)=10.84\right.$, $\mathrm{P}<0.05$, one-tailed) and place of origin (urban or rural) ${ }^{2}(2)=8.41, \mathrm{P}<0.05$, one-tailed) has significant preference on substance abuse. Therefore, the study, recommend the city administration and other stakeholders should have to design regulatory law to avoid substance selling out around the campus with cloth distance and further study should have to conduct on illicit drug abuse.
\end{abstract}

DOI: $10.7176 /$ RHSS/12-1-02

Publication date: January $31^{\text {st }} 2022$

\section{INTRODUCTION}

The human history of medication utilization is related to Substance abuse. Human creatures were utilizing substances for distinct pharmaceutical purposes. According to the report of UNDCP (2008) explained Marijuana was used for medical purposes starting from 2737 B.C. Due to this reason, substance abuse became trained within humankind. Substance abuse such as alcohol, khat, and tobacco has gotten to be one of the rising open wellbeing and socio-economic issues (Henok, 2015).

Substances for the most part characterized as substances other than nourishment, taken to alter the way the body or the intellect capacities. Substance abuse is consuming alcohol, khat, and tobacco frequently, despite the truth that it causes issues in their life. The effect caused by substance abuse may be related to work, personal life, or security (Odejide, 1994).

the predominance of substance abuse among adolescents is getting to be a growing ponder. The world Report of substance abuse clarified around 180 million individuals abuse substances. Among them, $90 \%$ of substance abusers are youthful individuals (UNDCP, 2008). Substance abuse initiated at an early age is commonly related to complex issues. This issue can be physical, mental, interpersonal, social, educational, legal, or otherworldly (Anju, Chandrakala, Sital, and Amrit, 2016).

The issue of substance abuse is also the primary concern of sub-Saharan Africa nations. Students engage in substance abuse at an early age. The study conducted in Kenya secondary school shows khat (miraa) is an exceedingly abused substance taken after by alcohol and cigarette (Komen, 2014). in support of this idea, the study conducted in Addis Ababa Ayer Tena secondary school also shows a high predominance of liquor, khat, and cigarette abuse among students (Henok, 2015). thus, substance abuse predominance at an early age has got to be a severe issue.

Additionally, there is a higher predominance of substance abuse in Ethiopia's higher educational institutions. The study conducted in Axum University appears the predominance of substance abuse is $45.9 \%$ (Gebreslassie, Feleke, and Melese, 2013) which is lower than Haramaya University (60\%) (Gezahegh et al; 2014). The societal acknowledgment of substance abuse and availability of substances are the main reasons for the distinction in the predominance of substance abuse among universities. In addition to that, a families' substance abuse encounter has its claim impact in predominance. For instance, the students from the family with substance abuse history are 
more likely involved in substance abuse (Gebrie, Alebel, Zegeye, and Tesfaye, 2018).

The expanded abuse of substances among adolescents particularly on university students has been the concern of the government. The predominance is appearing increase from year to year. Besides that, there are issues related to substance abuse that incorporate personal problems that impact unfavorably on relationships with others, family, colleges, and friends (Jacquelyn and Mary, 2002). Concurring to Mahalet (2011), substance abuse leads to a high rate of crime, fuel struggle, political, devout narrow-mindedness, assaulting, or suicide in society. It also influences the mental and physical conditions of abusers.

Regarding the impact of social factors, distinctive studies attempted to clarify different dimensions. The study conducted in Jimma and Makele university indicates accessibility of substances around the campus was the contributory factor for an increment of substances abuse (Wazema and Madhavi, 2015., Kidan, 2011). the study in Haramaya University states that accessibility of khat is high in the East Harerge region which, increased the prevalence of Khat higher than other universities (Gezahegn et al., 2014). Chewing Khat is satisfactory by some group of Ethiopian people. Many Ethiopians chew Khat for amusement especially, at the ends of the week, and for adjusting individuals who lost their family members (Abebaw, Atalay, and Charlotte, 2007). This social acknowledgment makes a favorable environment to its prevalence.

Ethiopia is one of the countries more or less under the influence of traditional societies. Everything is collectively owned. The neighborhood lives together and shares joy and hardship of life, where interests have converged and seem to overlap. Because of this, the entire community is rigidly tied in connection with socioeconomic and social cohesion, that sharing the same thought, neighborhood, pictures and feelings, stories, myths, values, and norms (Nora, 2013). Due to that, societal acknowledgment is imperative in deciding one behavior. Therefore, indeed in spite of the fact that Ethiopia is one of the collective societies in which personal character is highly influenced by gather standards, the studies conducted on students' substance abuse behavior at the university level gave a little concern for social Variables. In arrange to fill this gap this study was designed to evaluate the influence of social components (peer pressure, family history, and social acceptance of substance abuse and availability of substances in the close distance) on substance abuse behavior of Dire Dawa University undergraduate students.

\section{METHODOLOGY}

The study utilized a descriptive survey design. The descriptive survey design was selected in the study because it enables the current researcher to investigate events and draw conclusions based on the data gotten from a relatively representative sample of the population. According to Cohern (1994), a descriptive survey research plan helps the investigator to accumulate statistics at a specific point in time with the intention of describing the nature of a present situation or figuring out the widespread towards which existing circumstance can be compared or identifying the relationship that exists between unique events. The design used to be a mix of a quantitative and qualitative element in such a way that quantitative includes the questioner, and the qualitative element included the interview and document analysis.

The study employed in higher educational institutions of Dire Dawa city administrations The researcher selected this site for its familiarity and proximity with the study site. The target population of this study was Students of Dire Dawa University who enrolled in all undergraduate programs of 2018G.C and key informants. There are six colleges and thirty-three departments at Dire Dawa University. it is difficult to include all the target populations in the study.

The researcher has employed both stratified random sampling and purposive sampling to select students and key informants respectively. Initially, students were categorized under six schools (school of medicine, school of social and behavioral science, school of engineering, school of law, school of natural science, and school of business and economics). Then, further stratification was done based on year of study and sex. Finally, a systematic random sampling technique was applied to select 383 students from each year of study. Students from each year of study are allocated proportionally to their class size.

In addition, a purposive sampling technique was employed to select nine key informants. Such as proctors (dormitory security), University main get way securities, student dean president, guidance and counseling office chairperson, crosscutting issues directorate, community engagement directorate, discipline committee, community police, and student president office/anti-drug club representative. Besides, students recorded documents of behavioral problem due to substance abuse selected by using purposive sampling from the year 2013-2018 G.C. Sample size determination

Moreover, the sample size for the study was determined using the sample size determination formula, which is stated by Yamane (1967).

According to him, for a $95 \%$ confidence interval and level of precisions 0.05 , size of the sample should be

$\mathrm{n}=\mathrm{N} / 1+\mathrm{N}(\mathrm{e} 2)$

Where, $\mathrm{N}=$ Population is size 
$\mathrm{e}=$ level of precision

$\mathrm{n}=$ sample size

Therefore, the sample size will be $\mathrm{n}=10,736 / 1+10,736(0.052)$

$\mathrm{n}=383$

Finally, to allocate sample size of $\mathrm{n}$ to different stratum proportional allocation method was used which Bowley (1926) originally proposes. the required sample of study subjects were calculated using proportional to size allocation technique from each study year and sex stratum by using the calculated sample $(n=383)$, which is presented in the table below.

Sample size of each stratum (ni) should be

$\mathrm{ni}=(\mathrm{n}) \mathrm{Ni} / \mathrm{N}$

Where, $\mathrm{n}=$ sample size

$\mathrm{Ni}=$ population size of the with stratum

$\mathrm{N}=$ Population size

Table 1: summary of Population, sample and sampling technique

\begin{tabular}{|c|c|c|c|c|c|c|c|}
\hline \multicolumn{8}{|c|}{$\begin{array}{c}\text { Dire Dawa university regular undergraduate } \\
\text { students }\end{array}$} \\
\hline School & \multirow[t]{2}{*}{ Study year } & \multicolumn{3}{|c|}{$\begin{array}{l}\text { Population } \\
\mathrm{N}=(10736)\end{array}$} & \multicolumn{3}{|c|}{$\begin{array}{c}\text { Sample } \mathrm{n}= \\
383 \mathrm{n}_{\mathrm{i}}= \\
(\mathrm{n}) \mathrm{N}_{i} / \mathrm{N}\end{array}$} \\
\hline \multirow[t]{6}{*}{ Engineering } & & $\mathrm{M}$ & $\mathrm{F}$ & Total & $\mathrm{M}$ & $\mathrm{F}$ & Total \\
\hline & $1^{\text {st }}$ year & 1269 & 505 & 1774 & 42 & 18 & 63 \\
\hline & $2^{\text {nd }}$ year & 710 & 241 & 951 & 25 & 9 & 34 \\
\hline & $3^{\text {rd }}$ year & 625 & 233 & 858 & 23 & 8 & 31 \\
\hline & $4^{\text {th }}$ year & 772 & 331 & 1103 & 27 & 12 & 39 \\
\hline & $5^{\text {th }}$ year & 760 & 284 & 1044 & 27 & 11 & 38 \\
\hline \multirow[t]{3}{*}{ Natural and computational science } & $1^{\text {st }}$ year & 287 & 346 & 633 & 10 & 13 & 23 \\
\hline & $2^{\text {nd }}$ year & 317 & 339 & 656 & 12 & 12 & 24 \\
\hline & $3^{\text {rd }}$ year & 148 & 192 & 340 & 5 & 7 & 12 \\
\hline \multirow[t]{5}{*}{ Medical and health science } & $1^{\text {st }}$ year & 55 & 35 & 90 & 2 & 1 & 3 \\
\hline & $2^{\text {nd }}$ year & 74 & 49 & 123 & 2 & 2 & 4 \\
\hline & $3^{\text {rd }}$ year & 53 & 36 & 89 & 2 & 1 & 3 \\
\hline & $4^{\text {th }}$ year & 91 & 31 & 122 & 3 & 2 & 4 \\
\hline & $5^{\text {th }}$ year & 41 & 6 & 47 & 2 & 0 & 2 \\
\hline \multirow[t]{3}{*}{ Business and economics } & $1^{\text {st }}$ year & 441 & 265 & 706 & 16 & 9 & 25 \\
\hline & $2^{\text {nd }}$ year & 425 & 286 & 711 & 15 & 10 & 25 \\
\hline & $3^{\text {rd }}$ year & 175 & 354 & 529 & 6 & 13 & 19 \\
\hline \multirow[t]{3}{*}{ Social science and humanity } & $1^{\text {st }}$ year & 113 & 109 & 222 & 4 & 4 & 8 \\
\hline & $2^{\text {nd }}$ year & 90 & 136 & 226 & 3 & 5 & 8 \\
\hline & $3^{\text {rd }}$ year & 94 & 89 & 183 & 4 & 3 & 7 \\
\hline \multirow[t]{5}{*}{ Law } & $1^{\text {st }}$ year & 57 & 38 & 95 & 2 & 1 & 3 \\
\hline & $2^{\text {nd }}$ year & 38 & 22 & 60 & 1 & 1 & 2 \\
\hline & $3^{\text {rd }}$ year & 37 & 15 & 52 & 1 & 1 & 2 \\
\hline & $4^{\text {th }}$ year & 41 & 21 & 62 & 1 & 1 & 2 \\
\hline & $5^{\text {th }}$ year & 51 & 9 & 60 & 2 & 0 & 2 \\
\hline & Total & 6764 & 3972 & 10736 & 237 & 144 & 383 \\
\hline
\end{tabular}

The data collection instrument employed in this study was a Questioner, Interview, and document analysis. The questionnaire consists of three parts. the researcher used the questionnaire to obtain information about the thought, feeling, beliefs, values, and practices of research participants (Cohen, 1994). The questioners have three parts. The first part is about socio-demographic characteristics (sex, age, socio-economic status, family history, of the participants). The second part of the questionnaire measures the magnitude of substance abuse within 12 months. to assess the substance abuse history of students the CAGE-Aid screening too was employed. The screening tool has four questions with dichotomous responses (yes/No) which measure the addiction status of an individual. the Item responses on the CAGE questions are scored 0 for "no" and 1 for "yes" answers, with a higher score being an indication of alcohol problems. A total score of two or greater is considered clinically significant (Ewing, 1984. The inner consistency coefficient determined by the Kuder Richardson correlation is 0.92 . The item of the questionnaire measure social factors were adopted from the study of (Betelhem, 2014) and (Henok, 2015). The researcher modified the questionnaire in the context of the current study. The scale has split-half reliability of 0.8 . 
The interview items administered to nine Dire Dawa university administration staffs that have close contact with students such as proctors (dormitory security), University main get way securities, student dean precedent, discipline committee, guidance counseling office chairperson, crosscutting issues, community police and student president office. The items developed with English language and translated to local language (Amharic). Some of the key informants were at lower level of education, which hinder them to communicate English language fluently. Therefore, the interview administered by Amharic language. The data recorded both in written documents and in audio by using mobile apparatus.

After collecting the necessary data through questionnaire, the data edited to present in manageable way. The data acquired from questionnaire fed to SPSS version 20 for further quantitative analysis. The study had both independent and dependent variables. Social factor (family history, peer pressure, substance accessibility with close distance and societal acceptance of the substance abuse) was an independent variable and the dependent variable was student's substance abuse (alcohol, khat and tobacco).

Furthermore, in order to see association and contributions, the following methods implemented. To identify whether mentioned social factor significantly predict the student's substance abuse Binomial logistic regression used. By using Binomial, logistic regression research objective three which state about influence of social factor on substance abuse answered. Moreover, in order to see independence between socio-demographic variable (sex, café service utilization, place of residence and religious affiliation) and substance (khat, Alcohol and cigarette) abuse of student's chi-squire test of independence was implemented. The test answered research question four.

The study used Descriptive statistical analysis of mean, standard deviation, percentage and frequency. Frequency distribution and percentage used to analyze socio- demographic profile of the participants. Besides that, the descriptive statics of frequency distribution and percentage used also to analyze the first research question, which state about prevalence of substances abuse among students of Dire Dawa University. Whereas the mean and standard deviation employed to analyze the second research question which focus on magnitude of substance abuse among students. Descriptive frequency tables applied to observe the patterns of study respondent response to each of the study variables. On the other hand, Data Gathered from Key informants through interview and Document review presented by narration and interpreted on key points that were the objective of the study.

\section{RESULTS AND DISCUSSION}

\section{- Results}

Out of 383 students who invited to fill, questionnaire 350 students completed the questionnaire with a response rate of $91.4 \%$. The remaining questionnaires discarded due to inappropriate filling of the questionnaires.

the number of male students participated on the study was higher than their counterparts with proportion of $63.7 \%$. Besides, the participants age ranges from $20-23(66.57 \%)$ were higher with the mean of $20.4(\mathrm{Sd}+1.66$ Year). Most of the participants were orthodox Christian (30.0\%) followed by Muslim (27.1\%). Concerning the study year and college most of the participants were from first year $(28.6 \%)$ and higher number of participants were from college of engineering (33.4\%).

Prevalence of substance abuse and Main Abused Substance

Table 2: Lifetime prevalence of substance abuse among students

\begin{tabular}{|c|c|c|c|}
\hline \multirow[t]{2}{*}{ Substance } & \multicolumn{2}{|c|}{ Sex of respondents } & \multirow[t]{2}{*}{ Total } \\
\hline & female & male & \\
\hline \multicolumn{4}{|c|}{ Any substance abuse } \\
\hline No & $34(26.8 \%)$ & $83(37.2 \%)$ & $117(33.4 \%)$ \\
\hline Yes & $93(73.2 \%)$ & $140(62.8 \%)$ & $233(66.6 \%)$ \\
\hline \multicolumn{4}{|c|}{ Current cigarette abuse history } \\
\hline No & $85(66.9 \%)$ & $153(68.6 \%)$ & $238(68 \%)$ \\
\hline Yes & $42(22 \%)$ & $70(31.4 \%)$ & $112(32 \%)$ \\
\hline \multicolumn{4}{|c|}{ Current alcohol abuse history } \\
\hline No & $82(64.6 \%)$ & $132(59.2 \%)$ & $214(61.1 \%)$ \\
\hline Yes & $45(35.4 \%)$ & $91(40.8 \%)$ & $136(38.9 \%)$ \\
\hline \multicolumn{4}{|c|}{ Current khat abuse history } \\
\hline No & $51(40.2 \%)$ & $105(46.2 \%)$ & $154(44.0 \%)$ \\
\hline Yes & $76(59.8 \%)$ & $120(53.8 \%)$ & $196(56 \%)$ \\
\hline
\end{tabular}

Regarding lifetime abuse of substance 233(66.6\%) of students responded for substance abuse. Among them, $140(62.8 \%)$ were male. Furthermore, within substance abusers, Khat $(56 \%)$ was highly consumable substance followed by alcohol (38.9\%) and cigarette (32\%). As the finding indicates, the prevalence of substances abuse among study year was higher on students of fifth year, which followed by 4th and 3rd year students with the proportion of $58 \%, 62 \%$, and $64 \%$ respectively. In addition, the perception of students toward substance abuse also contributes to prevalence of substance abuse. Among the substance abusers $64.4 \%$ had perceived substance abuse as a useful practice. 
The in-depth interview records also support the quantitative result. All of the participants explained, as there was a high prevalence of substance abuse among Dire Dawa university students. The prevalence was very high on male students than female students. Furthermore, the universities declare rule and regulations, which withhold substance abuse within the university compound. However, the students were using secretly. Moreover, increases numbers of students, thinking of substance abuse as manifestation of modernization and inter connectedness among abused substances raised as aggravating reasons for prevalence and new incidence of substance abuse. One of the participants explains that:

"In the previous year using substances was considered taboo and students were abused secretly. Nowadays they believe in using the substance as modernization and practicing it in the public. taking substances within the university compound is forbidden. Perhaps we found students take khat into the university by hiding in a different part of their body. For instance, they cut off the fertile part of khat which is called (atterera), rolled it with a wrapper, and hide it in their underwear or within their socks."

In addition to that, the result of interview showed prevalence of substance abuse was causing different problems. Majority of participants raised substance abuse as a leading factor toward illicit drug use. As one of the interview respondents, explain that:

"I remember one student from the law department in the year 2010G.C. He was starting to abuse substances within the campus by the influence of his peer. Through time, they introduced him to illicit drugs, and he became a dealer of an illicit drug. Due to that reason, he was sentenced to the correction center for four years. After his release from the correction center, he started to abuse substances again, and finally, he lost his normality."

Magnitude of Substance Abuse among Students

Table 3: magnitude of substance abuse among students

\begin{tabular}{ccccccccc}
\hline \multirow{2}{*}{$\begin{array}{c}\text { Variable } \\
\text { (substance) }\end{array}$} & Never & Rarely & occasionally & Usually, & Often & Mean & Standard & Ran \\
Deviation & k student's substance abuse pattern (n=350) \\
Khat & $154(44 \%)$ & $26(7.4 \%)$ & $45(12.9 \%)$ & $90(26 \%)$ & $35(10 \%)$ & 4.78 & 0.57 & 1 \\
Alcohol & $214(61 \%)$ & $10(2.8 \%)$ & $25(7.14 \%)$ & $80(30 \%)$ & $20(5.7 \%)$ & 4.23 & 0.68 & 2 \\
Cigarette & $238(68 \%)$ & $10(2.8 \%)$ & $22(6.3 \%)$ & $60(17 \%)$ & $20(5.7 \%)$ & 4.01 & 0.81 & 3 \\
\hline
\end{tabular}

As table 2 reveals, the rating scale was employed to indicate the frequency of substance abuse within the last 12 months. 1 for never, $2=$ rarely, $3=$ occasionally $4=$ usually and $5=$ often. As the findings show, khat was frequently abused substance with mean of $4.78(\mathrm{Sd}+0.57)$ followed by alcohol and cigarette with mean of 4.23 and 4.01 respectively. Besides, according to the finding, the standard deviation of cigarette $(\mathrm{SD}=0.81)$ was higher than alcohol $(\mathrm{SD}=0.68)$ and khat $(\mathrm{SD}=0.57)$ which slightly higher dispersion from the mean score.

The qualitative data result also supports the quantitative finding as there was a high frequency (magnitude) of substance abuse among students. As the interview, result explains, staying long in campus, and the need for socialization was mentioned as a factor for the increased magnitude of substance abuse among the students. As one of the respondents, explains:

"Most of the time youths from the outside community were observed while they abused substances. the university students want to mix up with them. To make friends from the outside community, Fourth and fifthyear students are highly immersed in substance abuse. Besides, the students who spent most of their time with people who abuse substances will be attracted to substance abuse".

In addition, students affected by the increased magnitude also affecting the severely. As the result of the interview explained, class absentee raised as one major substance abuse related problem among students. one of the interviewees explained:

"Frequently the t first-class in the morning and afternoon class was missed. As a teacher, I know the students with repeated absentees in my class. Students "s drank alcohol faced the difficulty of waking early morning. Due to that, they miss classes. Those students who chew chat miss the afternoon class most regularly. Because during chewing their mood reached climax. To break the climax, they were drinking alcohol, which is called „, chebsi". For that reason, they are exposed to frequent class missing than other students. Sometimes I try to advise them not to do so. But they were unable to do it". 


\section{Social Factor Contributing to Students Substance Abuse}

Table 4: Binary logistic regression analyses table shows prediction of social factors on substance abuse of students

\begin{tabular}{lccc}
\hline Variable & \multicolumn{2}{c}{ substance abuse history of } & Crude \\
& No & yes & OR (95\% CI) \\
\hline Family substance abuse history & & & \\
No & $56(47.9 \%)$ & $48(20.6 \%)$ & 1.00 \\
Yes & $61(52.1 \%)$ & $185(79.4 \%)$ & $3.07(1.74,5.41)$ \\
Peer pressure & & & 1.00 \\
No & $86(73.5 \%)$ & $94(52.2 \%)$ & $2.3(1.79,5.22)$ \\
Yes & $31(26.5 \%)$ & $139(59.7 \%)$ & 1.00 \\
Substance availability & & & $6.52(2.76,7.92)$ \\
No & $0(0 \%)$ & $42(18 \%)$ & 1.00 \\
Yes & $117(100 \%)$ & $191(82 \%)$ & $3.04(4.56,5.21)$ \\
Societal acceptance of substances & & & $50(21.5 \%)$ \\
No & $50(42.7 \%)$ & $183(78.5 \%)$ & . \\
Yes & $67(57.3 \%)$ & & \\
\hline
\end{tabular}

As table 4 shows, in a binary analysis, social factors were significantly associated with substance abuse of students. The odd ratio of experiencing substance abuse was higher on students from substance abusive family. Similar to this the odd ratio of experiencing substance abuse was 6.52 times higher on availability $(\mathrm{COR}=6.52$ : 95\% CI 2.76, 6.92) and 3.04 times higher on social acceptance of substance (COR=3.04: 95\% CI 4.56, 5.21). That means the availability of substances was highly predictor of substance abuse. The odd ratio of Peer pressure $(C O R=$ 2.3: 95\% CI 1.79, 5.22) was higher than the students with low peer pressure.

The interview result also supports the idea that social factor predicts the substance abuse of students. The respondents raised different ideas about the contribution of social factors. The frequency of family substance abuse, previous students' substance buying experience for family consumption, and approval that the family gave toward substance abuse of students was mentioned as one of the influential factors for increased abuse of substances among students. Regarding family approval, one of the respondents explains:

"One of the students with a repeated record of a disciplinary case of substance abuse said as his father was a farmer and had a farm of khat. His father and older brother chew khat together most frequently. This practice was considered a normal deed within his family. Every month his parents sent him money for the sake of khat. They think chewing khat increases studying habits".

In contrary to the above finding, the interview data also show that the students from non- substance abusive family were also involved in to substance abuse. As one of the participants explained:

"There was a student from a religious family, and he was also highly attendant of the church. However, when he joins the university, he was involved in substance abuse. Following that, he was involved in illicit drug abuse. Then, he was arrested while using an illicit drug and sent to a correction center. Finally, his family called to student service to know the whereabouts of their child. The student service found out where the student was. But the student was crying most not to told the situation to his family."

Furthermore, peer influence also mentioned as another factor by the majority of respondents. Most of the students with substance abuse had friends abuse substance. Due to that, the need for having maintained friendship also another reason that forces the students to involve in substance abuse. One of the respondents explains:

"There was one student. She was new to the university and she went out spending the night with her girlfriend. Her girlfriend was inviting her to a birthday party where they celebrate by chewing khat and smoking 'shisha'. They invited her to do it once. Then after she smokes and chews khat until she exhausts. Finally, they went to a bar, got drunk and was dropped in one of their friend's homes. Unfortunately, she was exposed for gang-raping and they recorded the situation and kept the recording to disseminate it to social media."

Moreover, the interview result showed that substances especially alcohol and khat were highly acceptable by society and used in different social event and ritual ceremonies. The accessibilities of substance around the campus also show increment from year to year. Currently, more than 40 khat houses are found around the university that provides Khat, alcohol, cigarette, and other substances. Lack of regulatory law and regulation on services providers rose as a factor for increased availability. As one of the community police explains:

"If you go inside the village which is found around the campus, you may observe many khat houses. Some of the sellers prepare a place for khat chewing or , bercha bet" inside their homes. It was very hard for the university and community policies. Last time I found those who provide this service for students and we took a measure by burning of materials they used for any substance abuse purpose. After a short break, they also start service provision in another home where they can't be traced easily."

Besides, the finding shows the accessibility of substance benefit the community with profit making and on 
the contrary lead the students to develop misconduct in order to address their abuse need. One of the respondents explains:

"The service providers just focused on their benefit than students. When the students lost money to buy substance, they start to sell mobile scratch cards which their family send to communicate with them or stolen from their friends. The students sent 50-birr cards with a great discount from 30 --- 40 birr. This is known by all of the community residing around the campus."

In another, dimension the community also affected by the prevalence of substance abuse. Students from the outside community may develop wrong image toward campus and the university students may become a wrong model. Focused on this as one of the community engagement program Directorate explained:

"The community is highly harmed than the benefit they gain. Most of the time students abuse substance out of the campus where most children and youths observed them. Due to that youths may lose interest to join university or imitate their deed easily as good practice”.

Socio-demographic factor association with substance abuse of students

Table 5: the association of demographic variable with substance abuse students

\begin{tabular}{|c|c|c|c|c|c|c|c|}
\hline \multirow[t]{2}{*}{ Variable } & \multirow[t]{2}{*}{ Category } & $\begin{array}{r}\text { substance abu } \\
\text { respon } \\
\text { Frequen }\end{array}$ & $\begin{array}{l}\text { history of } \\
\text { its } \\
(\%)\end{array}$ & Total & \multirow[t]{2}{*}{2} & \multirow{2}{*}{\multicolumn{2}{|c|}{ Sig }} \\
\hline & & no & & & & & \\
\hline & female & $34(29.1 \%)$ & $93(39.9 \%)$ & $127(36.3 \%)$ & & & \\
\hline Sex of respondents & & & & & ${ }^{2}=3.514^{b}$ & .61 & \\
\hline & male & $83(70.9 \%)$ & $140(60.1 \%)$ & $223(63.7 \%)$ & & & \\
\hline $\begin{array}{l}\text { student service } \\
\text { status of respondents }\end{array}$ & $\begin{array}{l}\text { cafe service } \\
\text { none cafe }\end{array}$ & $58(49.6 \%)$ & $72(30.9 \%)$ & $130(37.1 \%)$ & ${ }^{2}=10.844^{b}$ & & .001 \\
\hline & users & $59(50.4 \%)$ & $161(69.1 \%)$ & $220(62.9 \%)$ & & & \\
\hline & Orthodox & $35(29.9 \%)$ & $70(30.0 \%)$ & $105(30.0 \%)$ & & & \\
\hline & Protestant & $20(17.1 \%)$ & $34(14.6 \%)$ & $54(15.4 \%)$ & & & \\
\hline & Muslim & $25(21.4 \%)$ & $70(30.0 \%)$ & $95(27.1 \%)$ & $\mathbf{2}^{2}=6.920^{\mathrm{a}}$ & .70 & \\
\hline Religious affiliation & Catholic & $14(12.0 \%)$ & $23(9.9 \%)$ & $37(10.6 \%)$ & & & \\
\hline & No religion & $13(11.1 \%)$ & $12(5.2 \%)$ & $25(7.1 \%)$ & & & \\
\hline & Other & $10(8.5 \%)$ & $24(10.3 \%)$ & $34(9.7 \%)$ & & & \\
\hline & Urban & $145(62.2 \%)$ & $198(56.6 \%)$ & $53(45.3 \%)$ & $\mathbf{2}^{2}=8.414^{\mathrm{b}}$ & & .004 \\
\hline Place of origin & Rural & $88(37.8 \%)$ & $152(43.4 \%)$ & $64(54.7 \%)$ & & & \\
\hline
\end{tabular}

As the above table 5 indicates, there is no preference among male and female students in substance abuse even though the prevalence is high on male students $(60.1 \%)$. The chi-square test indicated that there is no significant preference between both sexes with regard to substance abuse, $\chi^{2}(1)=3.514, \mathrm{P}>0.05$, one-tailed. In addition, the result shows non-cafe service was highly used by substance abusers than the non-substance abuser, which was $69.1 \%$ \& $50.4 \%$ respectively. The chi-square test analysis indicates that cafe service status has a significant preference among student's substance abuse, $\chi^{2}(1)=10.84, \mathrm{P}<0.05$, one-tailed. Regarding religious affiliation, the result shows students from different background abuse substances. The students from Muslim and orthodox religion take the first and the second place with $30.5 \%$ and $30 \%$ respectively. Besides that, the chi-square test analysis indicates there is no significant preference in religious affiliation regarding substance abuse, $\chi^{2}(5)=$ $6.920, \mathrm{P}>0.05$, one-tailed. Concerning place of origin, high numbers of the students who abuse substance were from urban with $56.6 \%$. In addition, the chi-squire test analysis in dictate that place of origin has a significant association with students' substance abuse, $\chi^{2}(2)=8.41, \mathrm{P}<0.05$, one-tailed.

The qualitative data also support the quantitative result. As the finding explains student's religion does not matter on substance abuse of students. Perhaps students with the experience of frequent attendance of religious service were more likely not to be involved in substance abuse. In addition, non-cafe service preference explained as no problem. However, due to searching cheap meal the students expose to different problems in relation to substance abuse. Besides, the students with high monthly income additional to money provided by the government for non-Cafe users more likely exposed to substance abuse. One of the students' service officers explains concerning non- cafe service utilization:

"I have heard one of the students explain the problem related with cheap cost meal. She said the amount paid for non-cafe service is very low. With this amount, feeding oneself properly was very difficult so that we need have to share with friends. Nevertheless, sometimes the friends needed to chew khat with them after lunch, which I do not want to do most. They always nag me to drunk at list one bottle of alcohol. For the sake of their happiness and to maintain my friendship I sometimes drink just one bottle alcohol”. 


\section{DISCUSSION}

This part of the thesis mainly deals with the discussion of the finding. The discussion organized under three themes such as prevalence of substance abuse, Magnitude of substance abuse and social factor association with substance abuse, which discussed in detail below.

\section{Prevalence of Substance Abuse}

The finding of the study reveals that $66.6 \%$ of the participants were abuse substance, which shows a high prevalence of substance abuse among students. This study is relatively closer with findings conducted in Haramaya University with 62.4\% (Gemechis et al., 2017, Gezahgh et al., 2014). The geographical area similarity contributed to the resemblance of the finding. In addition to that, the current finding is higher than the study conducted in Bahr Dar College (19.6\%), Axum University (27.9\%), and Mekele University (32.5\%) (Mulgeta, 2013. Gebresilasa et al., 2013., Kidan, 2011). The difference is due to accessibility and social acceptance toward substances abuse. Substance especially khat is highly accessible in the east Hararge region where the current study conducted.

Among substances, Khat was highly abused substance among students. (56\%) which is slightly closer to similar finding in Harar secondary school with a prevalence rate of 59\% (Mahalet, 2011).the reason for the similarity is the resemblance within the geographical area and social acceptance toward substance abuse. Besides, this study is higher than the finding in Addis Ababa University (31.4\%) Mekele University (25.4\%) and Mizantepi University (21.6\%)(Deresa and Azazh, 2011., kidan, 2011., Andualem, 2012). The possible justification for this high prevalence in our study could be, as explained by interview respondents khat is highly accessible in close distance around the university and chewing khat is a highly accepted practice within the community inside and outside the campuses.

Additionally, the Prevalence of khat was more on male (62\%) than female $(40.8 \%)$. Regarding female khat chewing the current finding is higher than the study conducted at Jima University on female students (2.4\%), Addis Ababa University study on medical college students (6\%), and study on south east Ethiopia in Ginnier town (8\%) (Wazema And Madhavi, 2015., Derrasa and azazh, 2011., Ahmed, 2014). The reason for the difference attributed to the accessibility of substance and social acceptance of substance abuse. The current study area is the eastern part of Ethiopia, known by its culture of chewing. Unfortunately, females also provided with khat even by family members. As the interview, Result explains in east Hararge chewing khat is the usual practice among women. Especially married women invited to chew khat by the husband. There are two purposes the woman chew khat. The first one is to generate energy to work high in energy demanding household activities and to recreate with their peers. Due to this, the female students of Dire Dawa University are highly influenced in relation to others.

In line with this, the prevalence of khat chewing was $62 \%$ among male substance abusers. This study is higher than findings of secondary school of Addis Ababa (37.3\%), and in kisumy town east, Keniya (52\%) (Alemnesh, 2014, Nyatuoro, 2012). The reason for the difference is age and family control. The students join universities who are the focuses of the current study are older, relaxed and out of family control than students enrolled in secondary school. In addition, the current study is higher than the study conducted at the University of Makele, Debre Birihan, and Addis Ababa with16.6\%, 62.7\% and 17\% respectively (Kidan, 2011., Bethlehem, 2014., Deresa and Azazh, 2011)

The study further reveals that proportion of alcohol drinking with $38.9 \%$ that is slightly closer to study of Haramaya University (41.7\%), Mekele University (41.1\%) and Addis Ababa public and private school (37.8\%) (Andualem, 2011, kidan, 2011, Rahel, 2017). Besides, the finding is lower than the study at Haramaya University (50.2\%), and Debre Birihan University (62.7\%) (Gezahagh et al, 2014., Bethlehem, 2014). The difference among the studies could be occurring due to the source population and high production of homemade alcoholic drinks than the current study area. The current finding is higher than the result from secondary school of Addis Ababa $(30.6 \%)$ (Alemnesh, 2014). The difference is attributing to age difference and diversity in study area.

Preceding to that the finding shows alcohol drinking was higher among male a student $(40.8 \%)$ which is greater than the study conducted at Ginier town (31.2\%) and Haramaya University (39.7\%) (Ahmed, 2014., Andualem, 2011). The reason for the difference is due to year gap among studies and sample size variation. Whereas the finding on drinking habit of female students $(34.5 \%)$, the result is higher than the study conducted at Addis Ababa university medical college (6\%) and Guiner town At south east Ethiopia(8.4\%) (Deresaa and Azazha,2011., Ahmed, 2014). The possible justification for this high prevalence in our study could be, as explained by interview respondents the interconnectedness among substance was the reason for increased substance abuse. The students with chewing habit most probably go to a bar to drink alcohol.

Moreover, concerning cigarette smoking, 32\% of respondents smoke cigarette which is prevalence was ranked in the third level. Similar to this funding studies from most universities such as Haramaya, Mizan-tepi, Addis Ababa, Mekale and Debre Birihan explain cigarette smoking as the third prevalent substance among students (Andualem, 2011., Andualem, 2012 Deresa and Azazh, 2011., kidan, 2011., Betelihem, 2014). Even though cigarette smoking is ranked in the third place, the prevalence is different from study to study. The current finding was similar with the prevalence rate of Harari region secondary school study with 30\% (Mahalet, 2011) but 
different with the study conducted in Makele university 19.6\%, Addis Ababa university 8.8\%, Haramaya University 11.3\% (kidan, 2011., Deresa and Azazh, 2011., andualem, 2011). The reason for difference is due to different Geographical area, high accessibility of substance around the campus and sampling size.

Furthermore the finding reveals that cigarette smoking of female students $(22 \%)$ was higher than the study conducted at Giunire town, mizan tepi university and secondary and preparatory school of Addis Ababa with proportion of 7\%, 12.5\% and 14.\&\% respectively (Ahimed, 2014., Andualem, 2012., Alemnesh, 2014). The reason for the difference is the age of the participants and knowledge about the side effect of cigarette Abuse. The smoking report of male (50.8\%) from the current study is higher than the report from Adis Ababa University, Mekele university and Gondar university (Deresaa and Azazha, 2011., kidan, 2011). The reason attributes toward the difference the interconnectedness of substance among each other. The one abuse khat more likely starts smoking.

Besides, the study found out the religious affiliation has no significant association with substance abuse $\chi^{2}$ $(5)=6.920, \mathrm{P}>0.05$. The students from different religious background abuse substance. The finding is similar with the study conducted at Jimma University, Mekelle University, Mizan-tepi University and Addis Ababa University (Deribachew, 2015., Kidan, 2011., Andualem, 2012., Derrasa and azazh, 2011). In addition, the study reveals that $69.1 \%$ of substance users were non-cafe service utilize. The non-café service also mentioned as the factor for increased prevalence. Similar to this, the study conducted in Makele also explained non-cafe service utilization as one of the contributory factors for increased substance abuse (Kidan, 2011).

\section{Magnitude of Substance Abuse}

The finding of the study reveals that the magnitude of substance abuse was higher among students. Khat is with high magnitude followed by alcohol and cigarette with mean of 4.78, 4.23 and 4.01 respectively. Regarding to pattern of substance abuse the participants chew khat daily $(61.3 \%)$ is more in number than those chew khat occasionally (20.6\%). The finding is higher than the finding of Jimma University with proportion of $45.9 \%$ daily base and $2.7 \%$ occasionally chew khat (Wazema and Madhavi, 2015). whereas the finding is lower from study of Haramaya university students those chew khat occasionally were $71 \%$ and daily were (29\%) (Gezahagn et al; 2014). The difference is due to gap in year of study, accessibility and sample size. The substances especially khat is more accessible with cheap cost around Haramaya University. Beside that the finding is higher than the study of Addis Ababa secondary school proportion of $6.5 \%$ daily and $10 \%$ occasionally (Alemnesh, 2014). the difference is attributed to age variation among sample population and accessibility of substance.

Concerning to the pattern of drinking alcohol $40 \%$ of students daily and $20.6 \%$, students were occasionally drunk alcohol. The finding is lower than Haramaya University finding with $66.2 \%$ daily and $33.8 \%$ occasionally drinking pattern (Gezahgn, 2014). The difference is due to sample population deference and year of study distinction. Henceforth, the study is higher than the secondary school finding of Addis Ababa (daily 8\% and 16.2\% occasionally) and south east Ethiopia (24\% daily and 21\% occasionally) (Alemnesh,2014., Ahmed,2014).

In addition to that the finding reveal that $32.6 \%$ of the students were smoke cigarette daily and $4.6 \%$ were smoke cigarette occasionally which is lower than Haramaya study and higher than the study of South east Ethiopia (Andualem, 2014., Ahmed, 2014). Moreover, study reveals that substance abuse magnitude increases as long as the study year increases. The magnitude is higher on $4^{\text {th }}$ and $5^{\text {th }}$ year. Whereas the study conducted in Haramaya university explain that the magnitude increases at $3^{\text {rd }}$ year (Andualem, 2014). The possible justification for this high prevalence in our study could be, as explained by interview respondents staying more years in university create need of Mixing up with the outside community to had resemblance and group conformity lead students more in sever abuse of substance.

\section{Social Factor and Substance Abuse}

Regarding social factor, the finding reveals that there is an association between social factors and substance abuse of students. As the finding shows, $70 \%$ of students have a family with substance abuse and among substance users, $79 \%$ of them have family with substance abuse. Family substance abuse experience is one of the contributory factors for substance abuse of the students. Similar to this study conducted at secondary school of Uasin Gishu East Sub-County, Kenya reveals that student who have a family with substance abuse are 2times more exposed for substance abuse than those students who have no family with substance abuse experience (komen, 2014).

The studies conducted at Addis Ababa secondary school (58.6\%) and Southeast of Ethiopia (41.3\%) also support this finding (Henok, 2015, Ahmed, 2014). perhaps the extent of influence is lower than the currents study. The difference is due to age difference among the sample population and the secondary school students are under the control of the family. In addition to that, the family substance abuse frequency also contributes to substance abuse of students. The current study reveals that $54.5 \%$ of the students abusers have family who abuses substance usually and often.

On the topic of peer influence, the finding indicates $59.7 \%$ of substance abusers influenced by pear to start substances. The study conducted at Mekele University is similar to the current finding with the proportion of $58.8 \%$ (kidan,2011). study conducted at Kenya secondary school students in Uasin Gishu east sub-country and Nairobi west district show high influence of peer on students substance abuse with $88.3 \%$ and $68 \%$ respectively ( komen, 
2014., Niatuoro, 2004). The difference attributed due to the difference in the study area and socio-cultural deference. The study is greater than the finding of at Gonder university Maraki campus (12.4\%), India (42.6\%) and Southeast Ethiopia (31.6\%) ( Desalegh, deribew, Belayneh and Gobeze 2013).

Regarding to Availability of substance $88 \%$ of students explained substance is available around the campuses. The odd of experiencing substance abuse is higher on availability with (COR=6.52: $95 \%$ CI $2.76,6.92)$. This finding is higher than study at Addis Ababa secondary school and Makale Campus with $21.2 \%$ and $22.3 \%$ respectively (Henok, 2015., Kidan, 2011). The differences due to the lack restricted rules regarding to providing substances at cloth distance to the schools and university. As the qualitative findings show more than 40, Khat bets around the campus, which increases accessibility with great speed. The finding is comparable with Kenya study at case of Bomburi location which state availability of substance with cloth distance around schools is highly influential on substance abuse (Boscow, Moses, Paul and Priscillah, 2012)

Moreover, the social acceptance of substance abuse is the other influential factor in the prevalence of substance abuse. The finding shows $71 \%$ of the respondents explain substance abuse as socially acceptable. Similar to the current finding the study conducted in Haramaya University also explain social acceptance is predictor to substance abuse (Gezahigh et al., 2014).beside that the finding is higher from the study conducted at Mekale University $(10.2 \%)$ and india (10.2\%) (Kidan, 2011., Arora et al., 2014). The difference attributed to the difference in geographical location and East Hararge known by the culture of substance abuse especially chewing khat.

\section{SUMMARY, CONCLUSION and RECOMMENDATION}

\section{Summary}

The main objective of this study was to examine the contribution of Social Factors to Students Substance Abuse in Dire Dawa University. To arrive at the intended objectives, the study was guided by the following basic research questions.

What are the major types of substance abused by students in Dire Dawa University?

What is the magnitude of substance abuse practiced among students of Dire Dawa University?

To what extent do the social factors contribute to the substance use of students in the university?

What kinds of relationship are found between demographic variables and substance use?

To address the above questions, descriptive survey research design was applied. The subjects of the study were Dire Dawa university undergraduate students of 2018G.c and key informants (as proctors (dormitory security), University main get way securities, student dean precedent, research and development team member (this office conducted different studies around student's behavior), guidance counselling office chairperson, crosscutting issues and student president office).

A total of 350 respondents 223(63.7\%) male, 127(36.3\%) female students and 8 key informants 3 female and 5 males were included in the study. The data gathered through questioner, interview and document analysis. Data gathered through questioner analysed using Frequency, Percentile mean, standard deviation, Ch-squire test analysis, and Binomial logistic regression. The data obtained from the interview and document analysis qualitatively analysed. Based on the analysed data, the following finding obtained.

The first research question addressed the issue related to the prevalence of substance abuse among under graduate students of Dire Dawa university. The result of the study revel shows there is high prevalence rate of substance abuse among students $(66.6 \%)$. the prevalence is higher among third- and fourth-year students. As the result reviles the magnitude of substance abuse is slightly higher among students (CAGE $\geq 2=39 \%$ ). Besides, Khat is frequently abused substance $(\mathrm{M}=4.78, \mathrm{SD}=0.57)$ followed by alcohol $(\mathrm{M}=4.23, \mathrm{SD}=0.68)$ and cigarette $(\mathrm{M}=4.01, \mathrm{SD}=0.81)$. Furthermore, the study explained substance abuse was a leading factor toward illicit drug abuse.

Furthermore, the study indicates that among social factors availability of substance in cloth distance around the campus was highly predictor of substance abuse $(\mathrm{COR}=6.52: 95 \% \mathrm{CI} 2.76,6.92)$ followed by family substance abuse history $(\mathrm{COR}=3.07: 95 \% \mathrm{CI} 1.74,5.41)$ social acceptance $(\mathrm{COR}=3.04: 95 \% \mathrm{CI} 4.56,5.21)$ and, peer pressure $(\mathrm{COR}=2.30: 95 \% \mathrm{CI} 1.79,5.22)$ among students. Besides the study reveal that the majority of respondents perceive substance abuse as a socially acceptable practice.

The study also revealed there is no significant preference on substance abuse among male and female students $\left({ }^{2}(1)=3.514, \mathrm{P}>0.05\right.$, one-tailed). whereas café utilization (café or non-café) $\left({ }^{2}(1)=10.84, \mathrm{P}<0.05\right.$, onetailed) and place of origin (urban or rural) ${ }^{2}(2)=8.41, \mathrm{P}<0.05$, one-tailed) has significant preference on substance abuse.

\section{Conclusion}

Based on the result of the study, the researcher concluded the following points.

The finding shows, there was a high prevalence of substance abuse among Dire Dawa university students. Khat is highly abuse substance followed by alcohol and cigarette. the prevalence of substance abuse is higher on 3rd, 4th and 5th-year students.

The students abuse substance is slightly higher (CAGE $\geq 2=39 \%$ ). Regarding to the magnitude of substance 
abuse, Kat is abuse with higher frequency than alcohol and cigarette.

The availability of substances in close distance around the campus is the high predictor of substance abuse among students followed by family substance abuse history, societal acceptance and peer pressure respectively. As Chi- square test result revels, there is no significant preference between male and female students in substance abuse. Whereas there is significant preference of students on café service utilization and place origin.

\section{Recommendation}

The following recommendations are suggested by the researcher:

The city administration and other stakeholders should have to design regulatory law to avoid substance selling out around the campus with cloth distance.

The university should prepare programs to enhance the capacity of students to resist peer pressure.

The university also needs to have organized counseling centers, particularly on substance abuse related problem.

The university should have to design a development project on the community engagement program to address the outside community in relation to the reciprocal effect of community and student's substance abuse.

The researchers should have to conduct further study on illicit drug and determinant factors.

The researchers should have to conduct further study cause of increased prevalence of substance abuse among female students east Harerge region

\section{REFERENCES}

Abebaw, F., Atalay, A., and charlotte,H. 2007. Alcohol and drug use in Ethiopia: past, present and future. Africa Journal of Drug and Alcohol Studies, 6 (1): 40-52.

Ahmed, Y.M. 2014. Assessment of Substance Use and Associated Factors among High School and Preparatory School Students of Ginnir Town Bale Zone, Southeast Ethiopia. American Journal of Health Research, 2 (6): pp 414-419.doi: 10.11648/j.ajhr. 20140206.25

A Knowledge Centre for Youth Substance Abuse Prevention. 2010. What Is Youth Substance Abuse Prevention? Support material for first-rate substance education. Series C: Educ- ational materials. Humak University of Applied Sciences

Alem A, Kebede D and Kullgren G. 1999. The prevalence and socio-demographic correlates of khat chewing in Butajira, Ethiopia. Acta Psychiatrica Scand;100: 84-91

Alemu G., Animuta A., Abriham Z., and Bekele T. 2018.prevalence and predictor of khat chewing Among Ethiopian university students: Asystematic meta- analaysis. PLoS ONE, 13(4)1-5 doi. Org/10.1371/jornal.pone.0195718.

Andualem, D. 2011. Assessment of Substance use and risky sexual Behavior among Haramaya University. B.Sc Thesis, Addis Ababa University, Addis Ababa Ethiopia.

Andualem, H. 2012. Sexual Violence and substance use among female Students of Mizan- Tep University. B.Sc Thesis, Addis Ababa University, Addis Ababa Ethiopia.

Alemnesh, D. 2014. Peer pressure among adolescent student: in case of selected Secondary And Preparatory School of Addis Ababa.MA Thesis, Addis Ababa University, Addis Ababa, Ethiopia.

Anju, P., Chandrakala S., Sital G. and Amrit P. 2016. Psychosocial Problems among Individual With Substance Use Disorder, Journal of Substance Use, 2(3): pp, 17-25. doi.org/10.1186/s13011-016-0072-3.

Arora A., Kannan, S., Gowri S., Choudhary S., Sudarasanan S., and . Khosla, P.P. 2016. Substance abuse amongst the medical graduate Students in Developing country, Subharti Dental College, Meerut, India. Journal of Addiction 143(2): pp 101-103 doi:10.4103/09715916.178617.

APA, 1994. Diagnostic and Statistical Manual of Mental Disorder, USA.

APA, 2002. Developing Adolescents. Washington Dc,maclean's Retrieved From http;//www.apa.org/pi/pii/develops.pdf 2002

Bandura A. 1960. Social learning theory. New York City, General learning press

Bandura A. and Walters R. H. 1963. The role of imitation in personality development. Journal of Nursery Education. 2(33): pp 207-2015.

Betelhem, B. 2014. The relationship between stress, coping behavior and substance abuse among Debrebirihan University Student. MA Thesis, Addis Ababa University, Addis Ababa, Ethiopia.

Bowley, A. 1926. Measure of precision attain in sampling. Bulletin of the International Statistical Institute, 22(1): 6-62. doi.org/10.1186/s13011-016-0075-3.

Burack R. 1999. Teenage sexual behavior: Attitudes towards and declared sexual activity the British journal of family planning, 24 (4): 8-145.

Clark, Khate. 2009. Handling peer pressure, New York. Harper colins

Cohen, L. 1994. Research method in education ( $4^{\text {th }} \mathrm{ed}$ ). New York. Routhledge.

Central statistical authority, 2007. Population and housing census of Ethiopia. Administrative report retrieved from www.csa.gov.et/censusreport 
David J. and Richard F.(2005). Investing in Your Community's Youth: An Introduction to the Communities That Care System. Edition Item (\#501968D-07-05). Printed in the United States of America, USA

Deresaa, W. and Azazh, A. 2011. Substance Use and Its predictors among Undergraduate Medical students of Addis Ababa University In Ethiopia.BMC Peblic Health 11, 600 doi:10.1186/1471-2458-11-660 retrieved from :http://www.biomedcentral.com/1471

2458/11/660/

Desalegh, B.M., Deribew, A.A., Belayneh, K.G. and Gobezie, T.T. 2013. Assessment on the Prevalence and contributing Factors of social drugs utilization among University of Gondar regular Undergraduate students, Maraki Campus. International journal of Pharma Sciences and Research, 5(8): 0975-9492

Drug Administration and Control Authority of Ethiopia, 2005. Hand Book on Substances of Abuse for Trainers. Addis Ababa, Ethiopia

The Food, Medicine and Health Care Administration and Control Authority, 2010-2015. Addis Ababa, Ethiopia.

Gebrehanna, et al., 2014. Prevalence and Predictors of harmful Khat Use among University Students in Ethiopia. Substance Abuse Research and Treatment. Addis Continental Institute of Public Health, Addis Ababa University, Ethiopia. Publication of Libert as Academia. 2014:845-51 doi:10.4137/SaRt.S14413.

Gebreslassie.M. Feleke.A and Melese.T. 2013. Psychoactive substances use and Associated factors among Axum university students, Axum Town, north Ethiopia, BMC Public Health, vol.13, article 693, 2013.

Gemechis,T.K., Atinafu,K.G., Bedasa,T.H., and Dagne,T.G., 2017. Psychoactive Substances Use and Determining Factors among Regular Undergraduate Students of Dire-Dawa University, Eastern Ethiopia. Science Journal of Public Health, 5(2): 68-76 doi: 10.11648/j.sjph.20170502.13.

Gezahegh, T., Andualem D. and Mitiku T.H. 2014. Substance use and associated factor Among university students in Ethiopia: across sectional study. Journal Addiction, 26, 1-8 Retrieved fromVolumehttp://dx.doi.org/10.1155/2014/969837

Gurmesa, T., Fessahaye, A., and Sisay,D., 2012. Risk sexual behavior and Predisposing Factors among students of Jima University, Ethiopia. Ethiopia Journal of Health Science, 22(3): 170-180.

Harper D. 2001. What is a peer? Online Etymology Dictionary: available at http://www.etymonline.com.

Henok, A. 2015. Exploring the trends and challenges of substance: in case among Ayer tena Secondary school Addis Ababa. .MA Thesis, Addis Ababa University, Addis Ababa Ethiopia.

Jacquelyn, H.G., and Mary,C. 2002. Developing Adolescents: reference for Professionals, ashington Dc, American psychological association

Jimma-Minne sota International Symposium on Mental Health and Substance Use(JIMIS). 2014. Confronting the Challenge of Mental Health and Substance Use Problems in Africa. Jimma University and the Khat Research Program. Jimma Universit y, Ethiopia

Jossor,R and JossorS.L. 1975. Adolescent Development and the onset of Alcohol. Journal of Studies on Alcohol $36,27-41$

Kidane, A. 2011. Psycho active substance abuse and intervention to stop abuse: in case among Students of Mekele University. Master Thesis. Addis Ababa University. Addis Ababa Ethiopia

Koem, M.K. 2014. Factors influencing drug abuse among secondary school students in Uasin Gishu east sub country of Kenya. MA Thesis, University of Nairobi, Nairobi Kenya

Kumar, R. 2005. Research mythology. London: SAGE Publication.

Lemis M, N. and Judah N, A. 2008. Drug dependence and abuse in Kenyan Secondary schools. Academic Journals, 3(10):304---308.

Medanit, w. 2011. The relationship between parental substance abuse and child Maltreatment: in Case of Addis Ababa preparatory schools. Master's Thesis. Addis Ababa University. Addis Ababa Ethiopia.

Mahlet, M. 2011 an assessment of drug abuse among secondary school Students of Harari Region. Master's thesis. Addis Ababa University, Addis Ababa Ethiopia

Moses, M.M., Bosco, K.M., Paul, S.C And Priscillah, W.M. 2012. Factors influencing to drug Abuse Among the youth in kanya: A case of Bamburi Location. Elixir International Journal 46(2012), 8259-8267

Muhammad Z., Sobia R., Rabia H., Junaid Q., Hira I., Muhammad,H. and FazalR.C. 2015.Drug abuse among students, Faculty of Pharmacy, Bahuddin Zakaryia University Multan, Pakistan. Pakistan Journal of Pharmaceutical Research, 1, 41-47; Retrieved fromhttp://pjpr.net

Mukhandia, E. 2014. Determinates of Drug abuse among secondary school students in Kenya at the case of Kabuchai sub country.MA Thesis, University of Nairobi, Kenya

National Drug Control Master Plan of FMHCACA . (2010-2015). Addis Ababa, Ethiopia.

National Institute on Drug Abuse. 2008. Understanding Drug Abuse and Addiction. National Institutes of Health. U.S. Department of Health and Human Services, USA

Nayatuoro, J.O. 2012. Environmental and Demographic factors Influencing drug and substance abuse among secondary school students in Kisumu Town east Kenya. B. ED Thesis, Keniyata University, Kenya

National Institute for Crime Prevention and the Reintegration of Offenders, 2015.Exploring Substance Use 
between South African Adult and Young Offenders.USA

Nora J., 2013. Models and theories of addiction and the rehabilitation counselor. Ma Thesis. Southern illionious university, Carbondale. retrieved from http://opensiuc.lib.siu.edu/gs_rp/478

Oak Monali. 2009. Negative and Positive Effects of Peer Pressure. Retrieve Fromwww.buzzle.com/artist/negative-and-positive-effects-of Peer pressure.html

Odejide, A.O. 1994. Alcohol and substance abuse problems and control Strategies in Africa: The Experience: A paper presented at the 9th pan African psychiatric conference, Yaba Psychiatric Hospital, Logos,Nigeria.

Otieno and Ofulla, 2009. Drug Abuse in Kisumu Town Western Kenya Tropical Institute of Community Health. Great Lakes University of Kisumu, Kenya.

Razieh T. 2014. Bandura's social learning theory and Social cognitive theory. Tehran, Iran. Research gate. Retrieved from http;//www.research gate.net/publication/267750204

Saul M. 2016. Albert Bandura Social Learning Theory. Retrieved fromhttp://www.simplypsychology.org/bandura.html

Seyoum, G. \& Ayalew, G.(1995). A report on rapid assessment of the situation of drug and Substance abuse in selected urban areas in Ethiopia prepared for MOH and UNDP. 9-45.

Theodoros, G. and Olga, T. 2014. Social learning conceptualization for substance abuse; Implication for therapeutic intervention. University of Crete Rethymo, Greece. The European journal of counseling 3(1), pp 69-88. doi:10.5964/ejcop.v3i1.23.

UNODCCP, 2002. A Participatory handbook for youth drug abuse prevention programs. A Guide for Development and improvement. Global Youth Network, New York UN Publication.

UNODC World Drug Report, 2014. United Nations publication, Sales No.E.14.XI.7. Vienna

UNODC, 2008. World Drug Report Executive Summary, United Nations Publication.

Wazema, D.H. And Madhavi, K. 2015. Prevalenc of khat abuse and associated factors among Science , 3(7):17511757 dio: http://dx.doi.org/10.18203/2320 6012.ijrms20150264

Wikipedia 2018. Tobacco retrieved from https://enm.wikipedia.org/wiki/Tobacco

Wikipedia, 2018. Psycho active drug retrieved from https://enm.wikipedia.org/wiki/Psychoactive drug

World Health Organization. 2014. Adolescent development. Retrieved from www.who.int/maternal-childadolesent/topics/adolesence/dev/en

Yemane Taro. 1967. Statistics an introductory analysis, 2nd Ed. New York: Harper and Row

Yigzaw, K., Tefera, A., Belete, A., Amsalu,F., Getu, D., Abera K., and Belay, T.2005.

A module on Substance Abuse for the Ethiopian Health Center Team. University of Gondar in collaboration with the Ethiopia Public Health Training Initiative. The Carter Center, the Ethiopia Ministry of Health and the Ethiopia Ministry of Education. Addis Ababa, Ethiopia. 